\title{
Autologous pubovaginal slings: back to the future or a lost art?
}

This article was published in the following Dove Press journal:

Research and Reports in Urology

18 January 2016

Number of times this article has been viewed

\author{
Shieh-Ling Bang \\ Mohammed Belal \\ Department of Urology, Queen \\ Elizabeth Hospital, Birmingham, UK
}

Correspondence: Mohammed Belal Department of Urology, Queen Elizabeth Hospital, Birmingham, Queen Elizabeth Medical Centre, Birmingham BI5 2TH, UK

Tel +44 I2I 6272000

Email mohammed.belal@uhb.nhs.uk

\begin{abstract}
Stress urinary incontinence (SUI) is an under-diagnosed problem affecting up to $50 \%$ of women worldwide. SUI is a source of psychological distress to the individual and also imposes a financial burden to the individual and the health care system. The role of surgery in the treatment in SUI has evolved steadily in the last two decades. The synthetic mid-urethral sling and its different insertion methods have gained widespread popularity and are now the most frequently used surgical interventions for women with SUI in Europe. As the use of synthetic slings becomes more widespread, an increasing number of complications are being reported. With the recent concerns surrounding the use of synthetic transvaginal meshes in organ prolapse surgery, synthetic slings have been put under further scrutiny. It is imperative for health care providers to be aware of the current issues associated with synthetic slings and the alternative surgical options available. Traditional autologous pubovaginal slings (PVS) have re-emerged as a viable alternative to synthetic slings in light of the issues with synthetic slings. The re-adoption of autologous PVS has however, been slow due to the technical difficulty of the surgery and perceived higher morbidity rates. In this article, we will discuss the various aspects of autologous PVS and its indications as an alternative to synthetic slings. We will also touch on the current evidence and controversies for synthetic mesh slings.
\end{abstract}

Keywords: autologous pubovaginal sling, stress urinary incontinence, synthetic sling, erosions

\section{Introduction}

Stress urinary incontinence (SUI) is a common problem affecting up to $50 \%$ of women worldwide. ${ }^{1}$ The autologous fascial pubovaginal sling (PVS) was popularized by McGuire and Lytton in 1978 who reported an 80\% success rate in patients with intrinsic SUI. The synthetic mid-urethral sling (MUS), which was first introduced by Ulmsten in 1996, have largely replaced the traditional autologous PVS and are now the most frequently used surgical intervention in Europe for women with SUI. ${ }^{2}$

Following the recent concerns regarding the use of transvaginal mesh in organ prolapse surgery, synthetic MUSs have been put under scrutiny. Scotland's Regional Health Boards have received a request from the acting Medical Director for the National Health Service (NHS) Scotland regarding the suspension of the use of implantation of synthetic mesh slings in pelvic organ prolapse surgery pending further investigations. ${ }^{3}$ It is important for health care providers to be aware of the current concerns surrounding synthetic MUSs and the alternative surgical options that are available.

In this article, we will discuss the indications and results for autologous PVS sling placement and its viability as an alternative to synthetic slings. We will also review the current evidence and controversies surrounding synthetic mesh slings. 


\section{Data extraction}

We performed a systematic search on PubMed and on the Internet using the keywords "autologous slings", "fascia slings", "synthetic slings", "mesh complications", and "stress urinary incontinence". Articles published in English between the years 1996 and 2015 were selected and vetted by both the authors. Animal and basic science studies were excluded from this review. Studies with multiple results published over a time period were all reviewed.

\section{Preoperative assessment and indications for autologous slings}

Preoperative evaluation is directed toward confirmation of the diagnosis of SUI and to exclude any concurrent urinary urgency symptoms. The presence of urinary urgency is recognized as the main cause of surgical failure in SUI surgery. ${ }^{1}$ Preoperative evaluation for all patients includes a detailed urogynaecological history, physical examination, and urodynamic testing to confirm the presence of SUI. Additional pertinent points in the history include the presence of factors that will compromise the quality of the rectus fascia graft. Some of these factors include prior urethral or organ prolapse surgery and pelvic irradiation. ${ }^{1}$ Specific urodynamic findings like the Valsalva leak point pressure and urethral pressure profile should be obtained, although this is not being performed uniformly.

\section{Operative procedure for autologous pubovaginal sling}

The first step of the surgery involves the harvesting of the rectus fascial graft. This is performed by making a Pfannenstiel incision $2 \mathrm{~cm}$ above the pubic symphysis with the dissection carried down to the rectus fascia. A $2 \mathrm{~cm}$ by $10-12 \mathrm{~cm}$ rectus fascia graft is marked out and the edges of the graft are dissected and freed from the underlying rectus muscle. Running sutures of Prolene ${ }^{\mathrm{TM}}$ 3-0 (Ethicon, Johnson \& Johnson, Somerville, NJ, USA) are stitched onto each end of the graft with the sutures left long.

The second step of the surgery involves dissection of the wall of the vagina to create space for the placement of the autologous sling. An indwelling catheter inserted pre-operatively ensures that the bladder is emptied. A Sims speculum or a Lonestar retractor (CooperSurgical Inc., Trumbull, CT, USA) can be used to facilitate dissection and visualization. At least $50 \mathrm{mLs}$ of local anesthesia ( $0.5 \%$ bupivacaine and $1: 10,000$ adrenaline) is injected into the vaginal epithelium for hydrodissection. In the author's opinion, this is the single most important step as it aids in opening up the retropubic space and prevents urethra or bladder injury during subsequent passage of the trocar. The bladder neck is identified by palpation of the catheter balloon. A vertical incision is made through the vaginal epithelium extending from $2 \mathrm{~cm}$ below the meatus to the level of the bladder neck. The dissection plane will be above the periurethral and pubocervical fascia.

The third step of the surgery is the creation of lateral vaginal flaps using a combination of sharp and blunt dissection. The flaps are then lifted up with Allis clamps and the ischiopubic ramus is palpated. Using the tip of the Metzenbaum scissors pointing upward, toward the ipsilateral shoulder, a window is created in the ipsilateral endopelvic fascia. The index finger is then placed over the urethra to push it medially and therefore, protecting the urethra during this step. The space between the endopelvic fascia and ischiopubic rami that has previously been hydrodissected out is then opened up by spreading out the scissor blades. It is crucial to stay underneath the ischiopubic rami to avoid injury to the urethra or bladder. The above steps are repeated for the contralateral side.

The fourth step involves placement of the graft. The ends of the graft sutures are tied to the blunt ends of the trocars and brought out through the vaginal incisions. By careful guidance behind the pubis, the trocars are brought out through the abdominal incisions. Ideally, a rigid cystoscopy with a 70-degree lens is then performed to check for any urethra or bladder injury before pulling out the trocars completely. The two free ends of the sutures are then pulled up while keeping an artery forceps in place between the fascia and periurethral tissue. The suture ends are then tied together above the rectus fascia with a finger placed underneath the knot to avoid excessive tension. This operation is then completed with closure of both vaginal and abdominal incisions.

\section{Synthetic mesh slings}

Synthetic MUS procedures have been proven to be an effective treatment for female SUI. The advantages of synthetic slings include a consistent sling material quality, predictable handling properties, and the assurance of sterility. As no autologous tissue is required, the usage of a synthetic sling also eliminates any harvest site related morbidities and patients undergoing the procedure have a shorter operative time and hospital stay compared to autologous sling patients.

The most commonly used synthetic sling material is polypropylene, a type 1 mesh material (Amid classification). ${ }^{1}$ Polypropylene has loosely woven strands with pore sizes of $80 \mu \mathrm{m}$, permitting passage of macrophages to allow better host tissue ingrowth. ${ }^{1}$ The comparison of the post-operative 
histological changes show a greater amount of ingrowth of fibroblasts into both the sling material and normal tissue for synthetic slings as compared to autologous PVS. ${ }^{1}$ The synthetic sling is a non-degradable material and hence, has the innate disadvantage of a higher incidence of sling erosion into the urethral or vaginal wall.

The common presenting symptoms of sling erosion include urgency, vaginal discharge, pain, or recurrent urinary tract infections. Most erosions are diagnosed at a median of 18 months after surgery. ${ }^{1}$ Patient factors, such as a history of radiotherapy or urethral atrophy, play a role in sling erosions. Technical factors such as excessive sling tension, a dissection plane that is too close to the urethra, or occult perforation into the bladder or urethra during dissection are also believed to be some of the factors resulting in sling erosions. ${ }^{4}$ Apart from the patient and technical factors previously mentioned, the incidence of sling erosions is also dependent on the composition of the sling material. Synthetic slings are 15 times more likely to extrude into the urethra and 14 times more likely to erode into the vagina compared to autologous, allograft, and xenograft slings. ${ }^{4}$

Most studies agree that erosions resulting from synthetic MUSs require complete removal of all foreign material. The repair on the areas of erosion are then buttressed by soft tissue coverage such as a Martius flap. Erosion related complications will invariably lead to loss of urethral tissue or urethral length which often necessitates complex reconstruction surgery or secondary continence restoration procedures. Continence rates after successful urethral reconstructions are much lower than primary continence restoration procedures at $56 \%{ }^{4}$

Patients with sling erosion complications can present with recurrent extrusion or erosions, chronic pain, or recurrent abscesses. Anecdotally, Ugurlucan et $\mathrm{al}^{5}$ described a 36 year-old woman with trans-obturator sling-related vaginal erosion resulting in recurrent obturator abscesses with fistula formation 4 years after the initial insertion. The patient subsequently underwent drainage of the abscess with excision of the fistulous tract and removal of the necrotic material. Leanza et $\mathrm{al}^{6}$ also reported a late presentation of a woman 4 years after her initial surgery with tape erosion associated with myositis and abscesses of the obturator muscles. Both of these patients had presented with groin pain and difficulty walking. These cases emphasize the importance of long-term follow-up of these patients as sling erosion can present with late onset disabling complications. Magnetic resonance imaging is sensitive in detecting these late complications.
Widespread litigation involving synthetic mesh-related vaginal erosions have led to the US Food and Drug Administration (FDA) issuing a statement expressing concerns that the synthetic MUS procedure is at risk of long-term complications. Out of 2,874 reported cases of mesh complications in the FDA Manufacturer and User Device Experience database for the period from January 1 to December 31, 2008, 1,371 were associated with SUI repairs. This correlates with an average annual reporting rate of $2 \% .^{7}$ The FDA has since issued a Public Health Notification in 2008 to inform clinicians and patients of adverse events related to the urogynaecological use of surgical mesh and provided recommendations on how to mitigate mesh-related risks and counsel patients. The FDA is still currently looking into the literature regarding synthetic sling-related complications in the treatment of SUI and will issue a final report when the review is completed. ${ }^{8}$

\section{Autologous PVS}

The two most commonly utilized autologous slings are the rectus abdominis fascia or fascia lata graft slings. The rectus abdominis fascia sling is preferred by most surgeons due to a greater familiarity with the abdominal wall anatomy and the relative ease of harvesting. Both of these autologous slings have otherwise been shown to be equally effective. ${ }^{1}$

The main advantage associated with autologous PVS is the negligible risk of erosion as they have minimal inflammatory and foreign body reaction. A study showed that the autologous graft remains viable with no signs of degeneration up to 4 years after the initial implantation. ${ }^{1}$ This has been postulated as one of the reasons for the increased long-term risk of vaginal erosion with synthetic MUSs. ${ }^{1}$

The disadvantages of autologous PVS include a longer operating time due to graft harvesting and repositioning of the patient. In addition, there are associated morbidities of the harvesting site such as bleeding and infection.

The success rates for autologous PVS in the treatment of SUI range from $46.9 \%$ to $90 \%$ with the longest follow-up period being 10 years $^{9}$ (Table 1). These results have to be interpreted with caution due to the heterogeneity of the outcome measures and the short length of follow-up. Different outcome assessment tools are used and the Bristol Female Lower Urinary Tract Symptoms Questionnaire and the King's College Health Questionnaire are used in placed of the standard International Consultation on Incontinence Modular Questionnaire. Khan et $\mathrm{al}^{9}$ reported their 10-year long-term results of a multicenter, randomized, controlled trial comparing tension-free vaginal tape, autologous PVS, and xenograft 
Table I Summary of important papers on autologous PVS

\begin{tabular}{|c|c|c|c|c|}
\hline Study & $\begin{array}{l}\text { Number of } \\
\text { patients evaluated }\end{array}$ & Age (years) & Study objectives & Inclusion criteria \\
\hline Khan et $\mathrm{al}^{9}$ & $\begin{array}{l}\text { Total: } 162 \\
\text { TVT (63) } \\
\text { AFS (6I) } \\
\text { Xenograft (38) }\end{array}$ & $\begin{array}{l}\text { TVT: } 61.2 \text { (mean) } \\
\text { AFS: } 59.4 \text { (mean) } \\
\text { Xenograft: } 62 \text { (mean) }\end{array}$ & $\begin{array}{l}\text { Multicenter, randomized, } \\
\text { controlled trial comparing the } \\
\text { long-term outcomes of TVT, } \\
\text { AFS, and xenograft sling } \\
\text { in the management } \\
\text { of female SUI }\end{array}$ & $\begin{array}{l}\text { Females (aged }>18 \text { years) with } \\
\text { clinically and UDS confirmed } \\
\text { SUI, requiring surgical } \\
\text { intervention after failed trial of } \\
\text { pelvic floor exercises }\end{array}$ \\
\hline Morgan et al ${ }^{10}$ & 247 & 54.5 (mean) & $\begin{array}{l}\text { To report the long-term outcomes } \\
\text { of PVS for the treatment of } \\
\text { type II and type III SUI. } \\
\text { To assess QoL impact }\end{array}$ & $\begin{array}{l}\text { Women with type II or III } \\
\text { SUI between } 1993 \text { and } 1996 \\
\text { diagnosed with fluoroscopic } \\
\text { UDS who received PVS }\end{array}$ \\
\hline $\begin{array}{l}\text { Athanasopoulos } \\
\text { et al" }\end{array}$ & 264 & 53 (mean) & $\begin{array}{l}\text { To evaluate the efficacy of the } \\
\text { autologous fascia rectus sling in } \\
\text { treating female SUI }\end{array}$ & $\begin{array}{l}\text { Women with SUI treated with } \\
\text { autologous rectus fascia PVS } \\
\text { between } 2002 \text { and } 2005 \text { by a } \\
\text { single surgeon }\end{array}$ \\
\hline
\end{tabular}

Albo et al ${ }^{12}$

Athanasopoulos and McGuire ${ }^{13}$

Linder and Elliott $^{14}$

Chou et al ${ }^{15}$
Total: 520

PVS

Group: 265

Burch group: 255

32

46.4 (mean)

10

57 (median)

98

SUI: 46

MUI: 52

52.2 (mean)

PVS group:

51.6 (mean)
Burch group:

trial comparing success rates

between autologous PVS and

Burch colposuspension

Retrospective single surgeon evaluation of the efficacy of the bulbourethral rectus autologous sling in treating male SUI

To evaluate a transobturator approach using AFS for the management of female SUI

To assess the results of autologous PVS in women with MUI using a validated outcome score and identified risk factors for failure
Women with stress predominant symptoms, a positive stress test and urethral hypermobility

Men with SUI treated from 200 I to 2004

All patients who underwent ATO MUS placement for female SUI

Women who received a PVS for SUI/MUI confirmed by history, physical examination, and/or VUDS from I 995 to 200 I 


Definition of outcome

Success: women reporting being completely "dry" or "improved"

at follow-up

Resolution of SUI: not mentioned. QoL impact: Urogenital Distress Inventory short form score $<20$ : high rate of satisfaction

Failure: more than one pad/day. Improved: one pad/day and only if this represented a reduction in pad use of $>50 \%$ and reported as "satisfactory" by the patient. Cure: no leakage per urethra. Patient satisfaction: yes/no answer to the single, global assessment question: "Are you satisfied with the outcome of the performed operation?" Success: negative pad test.

No urinary incontinence on 3-day bladder diary.

Negative cough and Valsalva stress test. No self-reported symptoms.

No retreatment for the condition

Cure: no leakage per urethra or minimal leakage requiring only one pad/day. Improved: the use of two pads/day only if this represented a reduction in pad use $\geq 50 \%$ and reported as satisfactory by the patient.

Failure: leakage requiring more than two pads/day

Success: patients reporting no leakage and no pad use

\section{Feriod}

10 years Success rates at I-year vs

(median)

10-years:

TVT: $93 \%$ vs $73 \%$

AFS: $90 \%$ vs $75.4 \%$

Xenograft: $61 \%$ vs $58 \%$

10-year results not statistically significant

$5 I$ months Complete resolution of SUI

(mean) with no urge

incontinence: $88 \%$

High rate of satisfaction: $92 \%$

27.8 months Cured and satisfied with

(mean) outcome of operation: $85 \%$

\section{Complication Conclusion}

rates

Reoperation for SUI rates: There is not enough evidence

TVT: $\mathrm{n}=2$ (3.2\%)

24 months Success rates were higher for PVS vs Burch procedure, for both the overall category of success ( $47 \%$ vs $38 \%, P=0.01$ ) and the category specific to stress incontinence ( $66 \%$ vs $49 \%, P<0.001)$

29.5 months Cured and satisfied: $46.9 \%$ (mean) No improvement: $53.1 \%$

4 months $\quad$ Success: $80 \%$ (median)

\section{Adverse events}

were more common in the sling group (UTIs, difficulty voiding, and postoperative urge incontinence) than in the Burch group (63\% vs $47 \%, P<0.001)$

Overall: $21.9 \%$ modestly effective technique
Cured: pad test $<\mathbf{8}$ g loss and diary showing no SUI/UI episodes in 24 hours

\begin{abstract}
3 years
\end{abstract} (median)
The cure/improved rate: SUI: $97 \%$

MUI: $93 \%$

(not statistically significant) Increasing number of preoperative urgency and UI episodes correlated directly with PVS failure $(P<0.048)$
AFS: $n=0$

Xenograft: $n=5$ (13.1\%)

Sling failure: $n=8$ (3.2\%)

Other complications: $4 \%$

Overall: $29.16 \%$

to suggest a difference in longterm success rates between AFS and TVT.

However, there is some evidence that "dry" rates for AFS may be more durable than TVT PVS are effective and durable, and significantly improve the QoL in patients with types II and III SUI

The free autologous rectus fascia sling is a highly effective technique for the treatment of female SUI with mild morbidity

Autologous fascial sling results in a higher rate of successful treatment of SUI but also greater morbidity than the Burch colposuspension

The free rectus fascia bulbourethral sling is a for the treatment of male SUI with mild morbidity. The use of this method seems that it is suitable for selected cases

Post operative retention of ATO urethral sling placement urine requiring intermittent appears to be technically catheterization for

24 hours: $n=1$

Abdominal wall hematoma: $\mathrm{n}=$ I Superficial wound infection: $\mathrm{n}=\mathrm{I}$

Perioperative cystostomy requiring transvaginal

repair: $\mathrm{n}=$ I

MUI group:

troublesome UUI $n=2$, recurrent SUI $\mathrm{n}=\mathrm{I}$, prolonged retention requiring surgical revision $\mathrm{n}=$ I

SUI group: de novo UUI $n=2$ feasible with excellent shortterm outcomes. Longer follow-up and larger series are needed for validation

\begin{abstract}
Women with MUI have a successful PVS outcome at a rate comparable to that in women with simple SUI. Increasing episodes of urgency and $\mathrm{UI}$ on the preoperative voiding diary correlated directly with surgical failure, while voiding frequently was associated with cure
\end{abstract}


Table I (Continued)

\begin{tabular}{|c|c|c|c|c|}
\hline Study & $\begin{array}{l}\text { Number of } \\
\text { patients evaluated }\end{array}$ & Age (years) & Study objectives & Inclusion criteria \\
\hline $\begin{array}{l}\text { Welk and } \\
\text { Herschorn }\end{array}$ & 33 & 57 (median) & $\begin{array}{l}\text { Retrospective single surgeon } \\
\text { review of experience with } \\
\text { autologous fascia PVS in the era } \\
\text { of the MUS }\end{array}$ & $\begin{array}{l}\text { Patients underwent autologous } \\
\text { PVS between } 2002 \text { and } 2009 \\
\text { and who have failed a median o } \\
\text { two previous incontinence } \\
\text { treatments }\end{array}$ \\
\hline Milose et a $\left.\right|^{19}$ & 66 & 56.2 (mean) & $\begin{array}{l}\text { To review the efficacy of } \\
\text { autologous PVS after failed } \\
\text { synthetic MUS }\end{array}$ & $\begin{array}{l}\text { Women who underwent } \\
\text { autologous PVS with rectus } \\
\text { fascia after } \geq \text { I failed synthetic } \\
\text { MUS from } 2007 \text { to } 2012\end{array}$ \\
\hline Lee et $\mathrm{a}^{20}$ & 84 & 6I (mean) & $\begin{array}{l}\text { Retrospective report on the } \\
\text { long-term PVS outcomes } \\
\text { between primary and secondary } \\
\text { autologous fascia PVS }\end{array}$ & $\begin{array}{l}\text { Women undergoing PVS } \\
\text { between } 1996 \text { and } 201 \mathrm{I}\end{array}$ \\
\hline Rodrigues et a ${ }^{26}$ & 232 & $\begin{array}{l}\text { Fascial group: } \\
47.3 \text { years (median) } \\
\text { Vaginal sling group: } \\
48.5 \text { years (median) }\end{array}$ & $\begin{array}{l}\text { To compare the long-term } \\
\text { results of SUI treatment } \\
\text { involving fascial or vaginal } \\
\text { sling operations }\end{array}$ & $\begin{array}{l}\text { Women with confirmed SUI } \\
\text { diagnosis urodynamically who } \\
\text { underwent fascial or vaginal } \\
\text { sling operations }\end{array}$ \\
\hline
\end{tabular}

slings in women with SUI. They reported success rates or "dry" rates that favored the autologous PVS with none of the patients in the autologous PVS arm requiring further intervention for persistent SUI. They concluded that the autologous PVS may be more durable than the tension-free vaginal tape in the long-term. ${ }^{9}$ Morgan et al looked into their 4-year study outcomes of 247 females with SUI who received autologous PVS, and reported an overall continence rate of $88 \% .{ }^{10}$ They concluded that autologous PVS are effective, durable, and significantly improve the quality of life in patients with both type II and III SUI. Athanasopoulos et al also reported a success rate of $85 \%$ in 264 patients with autologous PVS. ${ }^{11}$ 


Definition of outcome
Success: one or no pad/day
QoL impact: UDI-6 and IIQ-7.
American Urological Association symptom
Score
Cure: patient, physician and The Michigan
Incontinence Symptom Index reports of
no stress or Ul in the absence of requiring
any additional incontinence procedures

Success: UDI-6 question on SUI $\leq$ I, IIQ-7, Primary: QoL score measured by a visual analogue scale $\leq 3$, and no SUI re-treatment/ operation

Follow-up Results
period

16 months

(median)

\section{I4.5 months Cure: $69.7 \%$}

(mean) Patients with pure SUI were significantly more likely to be cured of all incontinence $(62.5 \%)$ than those women with MUI (30.0\%)

Surgical success rate:

Primary: $76 \%$

Secondary: $52 \%$

(median)

Secondary:

82 months

(median)

were not statistically significant for total UDI-6 score, IIQ-7, and QoL

between groups

\section{Cured: no pads}

Greatly improved:

rare dribbling episodes under extreme stress, but with no need for pads Improved: none to one pad/day Failure: continuing urine loss sufficient to disturb the whole day's activities.

Worse: urine loss was intensified or new symptoms resulted from the surgery

\author{
Fascial group: Cured: \\ 70.3 months Fascial group: $74.4 \%$ \\ (mean) Vaginal sling group: $61.5 \%$ \\ Vaginal sling \\ group: \\ 44.9 months \\ (mean)
}

\section{Complication Conclusion \\ rates}

A third of the patients had The autologous fascia PVS

postoperative urgency, and has reasonable outcomes in a

only one patient continued diverse population of patients, to use intermittent catheterization despite failure of other treatment modalities

Urinary retention

Even after a failed synthetic

$>2$ weeks: $12.1 \%$ mid urethral sling, autologous Bladder perforation: $6.6 \%$ PVS is effective and cured SUI Deep vein thrombosis: in $69.7 \%$ of cases I. $5 \%$

De-novo urgency and Frequency: 19\% Early postoperative urinary retention resolved with catheter drainage: $\mathrm{n}=3$ Intermittent catheterization morbidity. at follow-up: $n=2$

At long-term follow-up of average 7.4 years, primary and secondary PVS patients had comparable favorable functional outcomes with low Secondary PVS patients had lower success rates with higher rate of additional procedures

Urinary retention: Fascial Sling operations are a safe group $11.1 \%$ vs vaginal sling and efficacious option to group: $8.6 \%$ treat SUI.

Surgical complications Shorter efficacy and fewer were comparable between complications are observed in the groups

vaginal wall sling operations,

while durable results, but with a higher rate of voiding dysfunctions compromising the long-term clinical satisfaction may be observed after excessive urethral suspensions, as in fascial sling suspension

PVS with autologous rectus fascia is an effective treatment for SUI.

Increase in post operative urethral resistance, PVR $>100 \mathrm{~mL}$ and pre-operative Qmax $\leq 20 \mathrm{~mL} / \mathrm{s}$ are risk factors for postoperative voiding difficulty

Abbreviations: SUI, stress urinary incontinence; MUI, mixed urinary incontinence; PVS, pubovaginal sling; AFS, autologous facial sling; ATO, autologous transobturator: TVT, transvaginal tape; MUS, mid-urethral sling; UDS, urodynamics; VUDS, video urodynamics; UFM, uroflowmetry; PVR, postvoid residual urine volume; CMG, filling cystometry; PFS, pressure flow study; UTI, urinary tract infection; UI, urge incontinence; IIQ-7, Incontinence Impact Questionnaires; UDI-6, Urogenital Distress Index; QoL, quality of life; UUI, urge urinary incontinence.

The complication rate was $29.2 \%$, with postoperative urgency being the most common problem. They concluded that the autologous PVS is a highly effective technique for the treatment of female SUI with low morbidity rates.

The landmark trial by Albo et al ${ }^{12}$ (the Stress Incontinence Surgical Treatment Efficacy [SISTEr] Trial) comparing autologous PVS to Burch colposuspension reported a higher success rates for autologous PVS compared to Burch colposuspension at 24 months ( $47 \%$ vs $38 \%, P=0.01$ ). However, higher rates of complications such as urinary tract infections, voiding difficulty, and post-operative urge incontinence were reported in the autologous PVS group. ${ }^{12}$ 


\section{Male SUI}

With continual widening of the indications for autologous PVS in conjunction with development of novel methods of sling insertions, autologous PVS slings have been shown to be effective on selected cases of male SUI. Athanasopoulos and McGuire reviewed their results of the retropubic free rectus fascia bulbourethral sling in 32 men with SUI. ${ }^{13}$ Their definition of a cure was the absence of urinary incontinence or mild incontinence requiring only one pad per day. Forty-five percent of patients were cured and satisfied with the results with a mean follow-up 29.5 months. The advantages of rectus fascial slings are that they are cheap and easy to obtain with low risk of sling erosions. The authors conclude that the autologous PVS sling is a modestly effective and safe technique for the treatment of male SUI in selected cases. ${ }^{13}$

\section{Transobturator insertion of autologous PVS}

A small study of ten patients by Linder and Elliott reported on the results of transobturator insertion of fascial sling in females with SUI. ${ }^{14}$ Success was defined as the absence of urinary incontinence and no pad use. An 80\% success rate was reported at a median follow-up of 4 months. The authors concluded that the transobturator approach is a feasible technique using a fascial sling with excellent short-term outcomes. However, a study with a larger cohort of patients and a longer period of follow-up is required to validate this approach. $^{14}$

\section{Mixed urinary incontinence}

In addition to the treatment of simple SUI, the autologous PVS has also been reported to be effective in the management of mixed urinary incontinence (MUI). Chou et al reported their results on 131 women with MUI who underwent autologous PVS. ${ }^{15}$ The results showed that women with SUI and concurrent urge urinary incontinence have outcomes comparable to women with simple SUI at long-term follow-up of up to 7 years. Detrusor over activity was present in $26 \%$ of the women but was not a predictor of poor outcomes. ${ }^{15}$

Traditionally, autologous PVS is advocated for secondary or recurrent SUI surgery. Zimmern et al reported on the retreatment rates as part of the secondary analysis of the SISTEr and the Trial of Mid-Urethral Slings trials. ${ }^{16}$ Six percent of women were re-treated within 5 years after failure of standard anti-incontinence procedures with either injection therapy or autologous PVS. Shah et al retrospectively reviewed 189 patients with sling erosions after synthetic
MUS insertion. ${ }^{17}$ They described a single step surgery with concomitant autologous PVS with total or near total removal of synthetic sling materials and urethral reconstruction. They concluded that this procedure can be safely performed in efforts to treat existing SUI or avoid future surgery for SUI. Our opinion is that any salvage surgery should be reserved until the patient has fully recovered from the initial synthetic sling removal. Welk and Herschorn ${ }^{18}$ and Milose et a ${ }^{19}$ both retrospectively reviewed women with recurrent SUI after a failed synthetic MUS or who had suffered from sling complications with autologous PVS chosen as a salvage procedure. Up to $69 \%$ of women experienced improvement in symptoms and they concluded that autologous PVS provides reasonable outcomes even after a failed synthetic MUS. ${ }^{18,19}$ Lee et al published their long-term results of autologous PVS with a median follow-up of 7.4 years and reported comparable functional outcomes in both primary and secondary PVS patients with low morbidity rates. ${ }^{20}$

In addition to salvage surgery, PVS is also indicated in primary SUI with concomitant loss of urethra length due to trauma or in conjunction with simultaneous complex urethra reconstruction. ${ }^{1}$ The durability of the autologous PVS also allows expansion of the indications to include treatment of primary uncomplicated SUI in young women who engage in vigorous exercises, obese individuals, or situations with potential poor tissue healing such as connective tissue disorders or uncontrolled diabetes mellitus. Autologous PVS can also be considered in patients requiring long-term intermittent catheterization as they have a much higher risk of urethral erosions if synthetic slings are used.

The risk of erosions associated with autologous PVS is rare, with only anecdotal case reports available. Handa and Stone reported the first case of autologous PVS sling erosion in the mid-urethra of a 34-year-old woman which was identified during urethroscopy performed after a 10 -week history of urinary retention. ${ }^{21}$ Webster and Gerridzen reported on a 73-year-old woman who developed urethral erosion after an autologous PVS following 2 weeks of intermittent catheterization. ${ }^{22}$ Golomb et al reported on a case of autologous PVS erosion into the mid-urethra in a 46-year-old woman that occurred after a traumatic episode of urethral catheterization. ${ }^{23}$ These three cases were all treated with surgical excision of the graft without any serious complications.

The incidence of voiding dysfunction is reported to be higher in autologous PVS compared to synthetic slings, with rates ranging from $2 \%$ to $20.8 \% .^{24,25}$ Rodrigues et al reported on their long-term results in 232 women who underwent either 
autologous PVS or synthetic MUS procedures for SUI, with a higher rate of voiding dysfunction observed in the fascial sling group. ${ }^{26}$ Albo et al (SISTEr Trial) also reported a higher incidence of voiding symptoms in the fascial PVS group compared to the Burch colposuspension group. In addition, they noted that all of the subsequent surgical procedures performed for bladder outlet obstruction were in the PVS group. ${ }^{12}$ Risk factors for post-operative voiding dysfunction was studied by Mitsui et al. ${ }^{27}$ They identified the risk factors for prolonged post-operative intermittent self- catheterization after PVS surgery and these included a post void residual volume of $>100 \mathrm{mLs}$; Qmax $\leq 20 \mathrm{~mL} / \mathrm{s}$ in preoperative urodynamic study. Nonetheless, the various studies on PVS surgery have not been able to show a consistent set of preoperative factors that can predict post-operative outcomes. ${ }^{27}$

\section{Conclusion}

The autologous PVS is an effective and safe option for surgical treatment of primary and secondary SUI. It can be safely performed with a low morbidity rate and a negligible erosion risk in comparison to synthetic slings.

Moving forward, it is important for the clinician to obtain dedicated training in synthetic and/or autologous sling surgery. It is also the responsibility of the clinician to provide accurate pre-operative counseling to the patient and to ensure that the patient understands the procedure and the alternatives. It is very important that the risks associated with the synthetic sling treatment of SUIs and the possible longterm complications that may result in subsequent secondary procedures are made known to the patients.

\section{Disclosure}

The authors report no conflicts of interest in this work.

\section{References}

1. Wein A, Kavoussi LR, Novick AC, Partin AW, Peters CA. Campbell-Walsh Urology, 10th Ed. Saunders Elsevier; 2012.

2. European Association of Urology [homepage on the Internet]. Guidelines on Urinary Incontinence. European Association of Urology 2014. Available from: http://uroweb.org/wp-content/uploads/20-UrinaryIncontinence_LR.pdf. Accessed March 1, 2015.

3. BBC news [homepage on the Internet]. Scottish Health Secretary Alex Neil requests mesh implant suspension. Available from: http://www.bbc. co.uk/news/uk-scotland-scotland-politics-27884794. Accessed June 14, 2014.

4. Blaivas JG, Sandhu J. Urethral reconstruction after erosion of slings in women. Curr Opin Urol. 2004;14(6):335-338.

5. Ugurlucan FG, Ozsurmeli M, Bakir B, Saygili H, Yalcin O. Recurrent obturator abscess with spontaneous expulsion of the mesh after transobturator tape operation. Int Urogynecol J. 2013;24(12):2153-2155.

6. Leanza V, Garozzo V, Accardi M, Molino A, Conca M, Basile A. A late complication of transobturator tape: abscess and myositis. Minerva Ginecol. 2008;60(1):91-94.
7. US Food and Drug Administration [webpage on the Internet] Manufacturer and User Facility Device Experience Database (MAUDE). Available from: http://www.fda.gov/cdrh/maude.html. Accessed June 28, 2007.

8. Urogynecologic Surgical Mesh: Update on the Safety and Effectiveness of Transvaginal Placement for Pelvic Organ Prolapse, US Food and Drug Administration and Centre for Devices and RadiologicalHealth, July2011. http://www.fda.gov/downloads/medicaldevices/safety/ alertsandnotices/ucm262760.pdf. Accessed July 16, 2013.

9. Khan ZA, Nambiar A, Morley R, Chapple CR, Emery SJ, Lucas MG Long-term follow-up of a multicenter randomised controlled trial comparing tension-free vaginal tape, xenograft and autologous fascial slings for the treatment of stress urinary incontinence in women. $B J U$ Int. 2015;115(6):968-977.

10. Morgan TO Jr, Westney OL, McGuire EJ. Pubovaginal sling: 4-YEAR outcome analysis and quality of life assessment. J Urol. 2000;163(6): $1845-1848$.

11. Athanasopoulos A, Gyftopoulos K, McGuire EJ. Efficacy and preoperative prognostic factors of autologous fascia rectus sling for treatment of female stress urinary incontinence. Urology. 2011;78(5):1034-1038.

12. Albo ME, Richter HE, Brubaker L, et al. Burch colposuspension versus fascial sling to reduce urinary stress incontinence. $N$ Engl $J$ Med. 2007;356(21):2143-2155

13. Athanasopoulos A, McGuire EJ. Efficacy of the bulbourethral autologous sling in treating male stress urinary incontinence: a three-year experience from a single center. Int Urol Nephrol. 2010;42(4):921-927.

14. Linder BJ, Elliott DS. Autologous Transobturator Urethral Sling Placement for Female Stress Urinary Incontinence. J Urol. 2015;193(3):991-996.

15. Chou EC, Flisser AJ, Panagopoulos G, Blaivas JG. Effective treatment for mixed urinary incontinence with a pubovaginal sling. J Urol. 2003;170(2 Pt 1):494-497.

16. Zimmern PE, Gormley EA, Stoddard AM, et al. Management of recurrent stress urinary incontinence after burch and sling procedures. Neurourol Urodyn. Epub 2015 Jan 16.

17. Shah K, Nikolavsky D, Gilsdorf D, Flynn BJ. Surgical management of lower urinary mesh perforation after mid-urethral polypropylene mesh sling: mesh excision, urinary tract reconstruction and concomitant pubovaginal sling with autologous rectus fascia. Int Urogynecol J. 2013; 24(12):2111-2117.

18. Welk BK, Herschorn S. The autologous fascia pubovaginal sling for complicated female stress Incontinence. Can Urol Assoc J. 2012;6(1): $36-40$.

19. Milose JC, Sharp KM, He C, Stoffel J, Clemens JQ, Cameron AP. Success of Autologous Pubovaginal Sling after Failed Synthetic Mid Urethral Sling. J Urol. 2015;193(3):916-920.

20. Lee D, Murray S, Bacsu CD, Zimmern PE. Long-term outcomes of autologous pubovaginal fascia slings: is there a difference between primary and secondary slings? Neurourol Urodyn. 2015;34(1):18-23.

21. Handa VL, Stone A. Erosion of a fascial sling into the urethra. Urology. 1999;54(5):923.

22. Webster TM, Gerridzen RG. Urethral erosion following autologous rectus fascial pubovaginal sling. Can J Urol. 2003;10(6):2068-2069.

23. Golomb J, Groutz A, Mor Y, Leibovitch I, Ramon J. Management of urethral erosion caused by a pubovaginal fascial sling. Urology. 2001; 57(1):159-160.

24. Mason RC, Roach M. Modified pubovaginal sling for treatment of intrinsic sphincteric deficiency. J Urol. 1996;156(6):1991-1994.

25. Zaragoza MR. Expanded indications for the pubovaginal sling: treatment of type 2 or 3 stress incontinence. J Urol. 1996;156(5):1620-1622.

26. Rodrigues P, Hering F, Meler A, Campagnari JC, D’Império M. Pubo-fascial versus vaginal sling operation for the treatment of stress urinary incontinence: a prospective study. Neurourol Urodyn. 2004; 23(7):627-631.

27. Mitsui T, Tanaka H, Moriya K, Kakizaki H, Nonomura K. Clinical and urodynamic outcomes of pubovaginal sling procedure with autologous rectus fascia for stress urinary incontinence. Int J Urol. 2007;14(12): 1076-1079. 
Research and Reports in Urology

Dovepress

\section{Publish your work in this journal}

Research and Reports in Urology is an international, peer-reviewed, open access journal publishing original research, reports, editorials, reviews and commentaries on all aspects of adult and pediatric urology in the clinic and laboratory including the following topics: Pathology, pathophysiology of urological disease; Investigation and treatment of

urological disease; Pharmacology of drugs used for the treatment of urological disease. The manuscript management system is completely online and includes a very quick and fair peer-review system, which is all easy to use. Visit http://www.dovepress.com/testimonials.php to read real quotes from published authors.

Submit your manuscript here: http://www.dovepress.com/research-and-reports-in-urology-journal 